\title{
Intracellular K(+) Determination With a Potentiometric Microelectrode Based on ZnO Nanowires
}

Syed Usman Ali, Muhammad Asif, Alimujiang Fulati, Omer Nur, Magnus Willander, Cecilia Brännmark, Peter Strålfors, Ulrika Englund, Fredrik Elinder and Bengt Danielsson

\section{Linköping University Post Print}

N.B.: When citing this work, cite the original article.

(C2011 IEEE. Personal use of this material is permitted. However, permission to reprint/republish this material for advertising or promotional purposes or for creating new collective works for resale or redistribution to servers or lists, or to reuse any copyrighted component of this work in other works must be obtained from the IEEE.

Syed Usman Ali, Muhammad Asif, Alimujiang Fulati, Omer Nur, Magnus Willander, Cecilia Brännmark, Peter Strålfors, Ulrika Englund, Fredrik Elinder and Bengt Danielsson, Intracellular $\mathrm{K}(+)$ Determination With a Potentiometric Microelectrode Based on $\mathrm{ZnO}$ Nanowires, 2011, IEEE transactions on nanotechnology, (10), 4, 913-919. http://dx.doi.org/10.1109/TNANO.2010.2089696 Postprint available at: Linköping University Electronic Press http://urn.kb.se/resolve?urn=urn:nbn:se:liu:diva-69803 


\section{Intracellular $\mathrm{K}^{+}$determination with a potentiometric microelectrode based on $\mathrm{ZnO}$ nanowires}

Syed M. Usman Ali ${ }^{1,2, *}$, Muhammad H. Asif ${ }^{1}$, Alimujiang Fulati ${ }^{1}$, Omer Nur ${ }^{1}$, Magnus Willander ${ }^{1}$ Cecilia Brännmark ${ }^{3}$, Peter Strålfors ${ }^{3}$, Ulrika H. Englund ${ }^{3}$, Fredrik Elinder ${ }^{3}$ and Bengt Danielsson ${ }^{4,5}$

${ }^{1}$ Physical Electronics and Nanotechnology Division, Department of Science and Technology, Campus Norrköping, Linköping University, SE-60174 Norrköping, Sweden

${ }^{2}$ Department of Electronic Engineering, NED University of Engineering and Technology

University road, Karachi-75270, Pakistan

${ }^{3}$ Department of Clinical and Experimental Medicine, Division of Cell Biology, Linköping

University, SE-58185 Linköping, Sweden.

${ }^{4}$ Division of Pure and Applied Biochemistry, Lund University, SE-221 00 Lund, Sweden

${ }^{5}$ Acromed Invest AB, Magistratsv. 10, SE-226 43 Lund, Sweden

Abstract: The fabrication and application of an intracellular $\mathrm{K}^{+}$-selective microelectrode is demonstrated. $\mathrm{ZnO}$ nanowires with a diameter of 100-180 $\mathrm{nm}$ and a length of approximately $1.5 \mu \mathrm{m}$ are grown on a borosilicate glass microcapillary. The $\mathrm{ZnO}$ nanowires were coated by a $\mathrm{K}^{+}$-ionophore-containing membrane. The $\mathrm{K}^{+}$-selective microelectrode exhibited a $\mathrm{K}^{+}$-dependent potentiometric response versus an $\mathrm{Ag} / \mathrm{AgCl}$ reference microelectrode that was linear over a large concentration range $(25 \mu \mathrm{M}-125 \mathrm{mM})$ with a minimum detection limit of $1 \mu \mathrm{M}$. The measured $\mathrm{K}^{+}$concentrations in human adipocytes and in frog oocytes were consistent with values of $\mathrm{K}^{+}$concentrations reported in the literature. The sensor has several advantages including ease of fabrication, ease of insertion into the cells, low cost, and high selectivity features that make this type of sensor suitable to characterize physiologically relevant ions within single living cells.

Index Terms - ZnO nanowires, intracellular potassium ions, potentiometric nanosensor, ionophore membrane, human adipocytes, frog oocytes, nanotechnology.

\section{INTRODUCTION}

Potassium ions $\left(\mathrm{K}^{+}\right)$and other alkali metal ions play important roles in biological systems [1]. For example, $\mathrm{K}^{+}$participates in the regulation of the resting membrane potential of a cell and consequently affects excitability and other physiological functions of nerve and muscle [2-3].

Manuscript received April 29, 2010; revised August 9, 2010.Resubmit revised manuscript on September 03, 2010, Accepted on October 16, 2010, First published April 3, 2009; current version published November 11, 2009. The review of this paper was arranged by Associate Editor B. Nelson.

S. M. Usman Ali is with the Department of Science and Technology, Linköping University, SE-601 74 Norrköping, Sweden, and also with the Department ofElectronic Engineering, NED University of Engineering \& Technology Karachi, Pakistan

E-mail: syeal@itn.liu.se

Muhammad H. Asif, Alimujiang Fulati, Omer Nur, Magnus Willander are with the Department of Science and Technology, Linköping University, SE-601 74 Norrköping, Sweden, (e-mail:

Muhammad.asif@itn.liu.se, alimpolat@gmail.com,magwi@itn.liu.se and omeno@itn.liu.se).

Cecilia Brännmark, Peter Strålfors, Ulrika H. Englund, Fredrik Elinder are with Department of Clinical and Experimental Medicine, Division of Cell Biology, Linköping University, SE-58185 Linköping, SwedenE mail; Cecilia.Brannmark@gmail.com , Peter.Stralfors@liu.se, Ulrika.Englund@liu.se Fredrik.Elinder@liu.se

B. Danielsson is with the Division of Pure and Applied Biochemistry,

Lund University, SE-22100 Lund, Sweden and also with Acromed

Invest AB, Magistratsv. 10, SE-226 43 Lund, Sweden

E-mail: bengt.danielsson@tbiokem.lth.se

Digital Object Identifier10.1109/TNANO.2010.2089696

Copyrights IEEE Transaction on nanotechnology.
Only about $2 \%$ of the total body $\mathrm{K}^{+}$resides in the extracellular fluid and its levels are crucial to normal homeostasis [4]. Hypo- and hyperkalemia are the most commonly encountered electrolyte abnormalities in hospitalized patients [5-6], and both alter the resting membrane potential, which can lead to ventricular fibrillation, cardiac arrest and sudden death without any warning clinical signs [7]. Since the abnormal $\mathrm{K}^{+}$ concentration in blood correlates with several diseases, the monitoring of $\mathrm{K}^{+}$in blood has become an important challenge. Various studies have described $\mathrm{K}^{+}$sensors based on ion-selective electrodes [8], homogeneous fluorescent $\mathrm{K}^{+}$sensing [9-10] and $\mathrm{K}^{+}$sensing based on quadruplex-forming oligonucleotides [11-12]. However, $\mathrm{K}^{+}$not only plays a critical role in the extracellular solution. $\mathrm{K}^{+}$is the main intracellular ion in the body where it participates in several vital functions, such as a cell growth, maintenance of cell volume, DNA and protein synthesis, enzymatic activity, acid base balance, and cellular apoptosis [13]. The purpose of the present investigation is to develop a simple method to determine the intracellular $\mathrm{K}^{+}$concentration.

Recently, chemical sensing based on a wide variety of nanostructures such as $\mathrm{ZnO}$ nanowires have attracted great interests in the applications of biosensors due to their remarkable properties like non-toxicity, biosafety, excellent biological compatibility, high-electron transfer rates, enhanced analytical performance, increased sensitivity, easy fabrication and low cost [14-19]. The high isoelectric point of $\mathrm{ZnO}$ (IEP 9.5) makes it a good matrix to immobilize low isoelectric point acidic proteins 
or DNA by electrostatic interactions with high binding stability [20-22]. In addition, $\mathrm{ZnO}$ has high ionic bonding $(60 \%)$, and its dissolution is very slow at biological $\mathrm{pH}-$ values. Due to these various advantages, stable and reproducible signals with respect to analyte-concentration changes are expected to be obtained. Among a variety of nanosensor systems, our proposed nanowire electrochemical sensor is one that can offer high sensitivity, high selectivity and real-time detection, suitable for diagnostic applications.

Intracellular sensors for nutrients such as sugars, metabolic precursors and signaling ligands such as amino acids will help to elucidate the complex roles of these small molecules in biology. Different biosensors have been used for real-time detection, diagnosis, and classification of different forms of biochemical reactions within single cells in order to understand cellular behavior. Such biosensors offer an enormous potential to cell biology research development [23-26]. In most of the intracellular biosensors, an indirect method or a large experimental setup is usually required. A simple technique that utilizes direct intracellular measurement would be of great interest. In our earlier investigations, we have used $\mathrm{ZnO}$ nanorods to measure the concentrations of intracellular $\mathrm{Ca}^{2+}$ and intracellular glucose [27-28]. In this work, we describe the construction of a simple and highly $\mathrm{K}^{+}$-selective sensor, capable of penetrating the cell membrane. The sensor is based on $\mathrm{ZnO}$ nanowires coated with a thin ionophorecontaining polyvinyl chloride (PVC) membrane. A ZnO thin film may also be used but we chose $\mathrm{ZnO}$ nanowires due to the higher surface-to-volume ratio thus capturing more ions on the $\mathrm{ZnO}$ structure also because the nanosurfaces have other chemical properties. These are the reasons why nanowires are more sensitive, have an extended detection limit and a fast response time as compared to a thin film [29-30]. The PVC-based polymer membranes have been successfully applied in many fields such as the monitoring of food production, environmental pollution and pathological specimens [31-33]. The $\mathrm{K}^{+}$selective microelectrode exhibited a linear electrochemical response (EMF) versus an $\mathrm{Ag} / \mathrm{AgCl}$ reference microelectrode over a wide range of $\mathrm{K}^{+}$ concentrations, and it was used in measuring $\mathrm{K}^{+}$in human adipocytes and Xenopus laevis oocytes. The results showed good performance in sensitivity, stability, selectivity, reproducibility, and anti-interference.

\section{EXPERIMENTAL DETAILS}

\subsection{Materials and preparation of the $\mathrm{K}^{+}$- selective membrane}

Valinomycin, PVC, potassium tetrakis (4chlorophenol) borate, bis-(2-ethylhexyl) sebacate, dibutyl phthalate (a plasticizer), $\mathrm{Zn}\left(\mathrm{NO}_{3}\right) 6 \mathrm{H}_{2} \mathrm{O}$ and hexamethylenetetramine, were purchased from Sigma Aldrich. Borosilicate glass capillaries (sterile Femtotip® II with tip inner diameter of $0.5 \mu \mathrm{m}$, tip outer diameter of
$0.7 \mu \mathrm{m}$, and length of $49 \mathrm{~mm}$ ) were purchased from Eppendorf AG, Hamburg, Germany. Phosphate-buffered saline (PBS) solution contained $8 \mathrm{mM} \mathrm{Na}_{2} \mathrm{HPO}_{4}, 1.5 \mathrm{mM}$ $\mathrm{KH}_{2} \mathrm{PO}_{4}$, and $135 \mathrm{mM} \mathrm{NaCl}$, with $\mathrm{pH}$ adjusted to 7.4. All chemicals used were of analytical reagent grade. The PVC membrane is a thin monolayer and contains the ionophore valinomycin, which has an excellent selectivity for $\mathrm{K}^{+}$. The molecular structure of valinomycin reminds about the selectivity filter in a $\mathrm{K}^{+}$selective ion channel [34-35]. $\mathrm{K}^{+}$will then, selectively, interact with the $\mathrm{ZnO}$ nanowires. By adjusting the number of the ionophores in the membrane, the life time and the response time of the sensor can be improved. The coating is conformal. The $\mathrm{K}^{+}$-selective PVC cocktail had the following composition: $1 \%$ ionophore, $33 \%$ PVC membrane and $66 \%$ plasticizer [36]. Finally the membrane coating was prepared by dissolving the composition in tetrahydrofurane.

\subsection{Fabrication of the $\mathrm{K}^{+}$-selective microelectrode}

To develop $\mathrm{K}^{+}$-selective and $\mathrm{Ag} / \mathrm{AgCl}$ reference microelectrodes for the electrochemical measurements, we appended the borosilicate glass capillaries carefully inside a flat support of the vacuum chamber of an evaporation system (Evaporator Satis CR725) to uniformly deposit chromium and silver films (with thick nesses of 10 and $125 \mathrm{~nm}$, respectively) at the outer surface of the capillary tips. After the evaporation steps, the silver covered microelectrode was dipped into $0.2 \mathrm{M}$ $\mathrm{HCl}$ solution and a $3-\mathrm{cm}$ long $\mathrm{Ag} / \mathrm{AgCl}$ layer was coated on the tip by electrolyzing the silver film by polarizing it at $1.0 \mathrm{~V}$ for $1 \mathrm{~min}$. Finally the electrode was covered with insulating material, leaving $3 \mathrm{~mm}$ of $\mathrm{Ag} / \mathrm{AgCl}$ exposed at the end of the tip to serve as a reference electrode.

To fabricate the $\mathrm{K}^{+}$-selective microelectrode, we grew $\mathrm{ZnO}$ nanowires on another chromium and silvercoated capillary glass tip using a low-temperature method [37-39]. To grow the nanowires on the capillary tip, the capillary tip was first carefully dipped into a seed solution for two minutes and then dried in air. This procedure was repeated twice. The seed solution $\begin{array}{lllllll}\text { contained } & 0.025 & \mathrm{M} & \mathrm{Zn}\left(\mathrm{NO}_{3}\right)_{2} & \text { and } & 0.025 & \mathrm{M}\end{array}$ hexamethylenetetramine. The solution was kept at $90{ }^{\circ} \mathrm{C}$ during the growth of $\mathrm{ZnO}$ nanowires. Subsequently, the capillary tip was carefully washed by deionized water and dried at room temperature. The $\mathrm{ZnO}$-nanowire layer covered a small part of the silver-coated film (0.01-3 $\mathrm{mm})$. The grown $\mathrm{ZnO}$ nanowires aligned perpendicularly to the capillary surface, as shown in figure $1(a-b)$. The nanowires were uniform in size with a diameter of 100 $180 \mathrm{~nm}$ and a length of approximately $1.5 \mu \mathrm{m}$. The $\mathrm{K}^{+}-$ selective membrane was coated onto the $\mathrm{ZnO}$ nanowires by dipping the electrode in the membrane solution for few minutes and leaving it to dry in the air at room temperature for 2.5 hours. A scanning-electron microscope image of membrane-coated $\mathrm{ZnO}$ nanowires is shown in figure 1(c). The electrical contact was made on the other end of the Ag film for obtaining an electrical 
signal during measurements. A main effort has been directed to make the tip geometry of intracellular electrodes extremely sharp (submicrometer dimension) and long enough $(>10 \mu \mathrm{m})$ to be manipulated into small living cells. These characteristics are necessary for effective bending and gentle penetration of the flexible cell membrane.

\subsection{Measurements and calibration}

The $\mathrm{K}^{+}$-selective intracellular measurements were carried out by a potentiometric method using the two microelectrodes described above. The electrochemical response between the electrodes was measured with a Metrohm $\mathrm{pH}$ meter model 827. For the time response measurements, a model 363A potentiostat/galvanostat (EG \& G Ltd, USA) was used. Initially we performed extracellular measurements for calibration using a standard $\mathrm{Ag} / \mathrm{AgCl}$ reference electrode. The $\mathrm{Ag} / \mathrm{AgCl}$ reference microelectrode was calibrated against the standard $\mathrm{Ag} / \mathrm{AgCl}$ reference electrode. The calibration results showed approximately the same potential difference in all $\mathrm{K}^{+}$solutions for concentrations ranging from $1 \mu \mathrm{M}$ to $125 \mathrm{mM}$. This potential difference was added to the data obtained with the reference microelectrode.

\subsection{Preparation of adipocytes and oocytes}

Human adipocytes were isolated by collagenase digestion of pieces of subcutaneous adipose tissue [40] obtained during elective surgery at the university hospital in Linköping, Sweden. All patients gave their informed consent, and procedures were approved by the local ethics committee. The adipocytes were incubated overnight before use as described by reference [40] and used in a Krebs-Ringer solution buffered with $20 \mathrm{mM}$ HEPES, pH 7.4 and with additives, as in [41]. A glass slide $(5 \mathrm{~cm} \times 4 \mathrm{~cm}$ and $0.17 \mathrm{~mm}$ thick) with sparsely distributed adipocytes was placed on a pre-warmed microscope stage set at $37^{\circ} \mathrm{C}$.

Female Xenopus laevis were anesthetized in a bath with tricaine (1.4 g/L, Sigma-Aldrich, Sweden), and ovarian lobes cut off through a small abdominal incision (procedure approved by the local ethical committee). Oocytes were manually dissected into smaller groups and defolliculated by enzymatic treatment with liberase (Roche Diagnostics, Sweden) for $2.5 \mathrm{~h}$. Stage VI oocytes (approximately $1 \mathrm{~mm}$ in diameter) without spots and with clear delimitation between the animal and vegetal pole were selected. Oocytes were kept in a modified Barth's solution (MBS in mM: $88 \mathrm{NaCl}, 1 \mathrm{KCl}, 2.4 \mathrm{NaHCO}_{3}, 15$ HEPES, $0.33 \mathrm{Ca}\left(\mathrm{NO}_{3}\right)_{2}, 0.41 \mathrm{CaCl}_{2}$ and $0.82 \mathrm{MgSO}_{4}$; $\mathrm{pH}$ adjusted to 7.6 by $\mathrm{NaOH}$ ) supplemented with pyruvate $(2.5 \mathrm{mM})$, penicillin $(25 \mathrm{U} / \mathrm{mL})$ and streptomycin $(25 \mu \mathrm{g} / \mathrm{mL})$ at $11^{\circ} \mathrm{C}$ for $1-5$ days before measurements. The measurements were carried out at room temperature $\left(20-23 \quad{ }^{\circ} \mathrm{C}\right)$. The experimental procedures are described in more detail by [42].

\section{Results and discussion}

The construction of the standard two-electrode electrochemical potential cell can be described by the diagram below:

$$
\mathrm{ZnO}_{\mathrm{s}}\left|\mathrm{Zn}^{+2}{ }_{\mathrm{PBS} \text { sol }}\right| \mathrm{Ag} / \mathrm{AgCl} \text { PBS sol } \mid \mathrm{Ag}^{\prime \prime}
$$

The cell voltage varies when the composition of the test electrolyte is changed. These changes can be related to the concentration of ions in the test electrolyte following the calibration procedure. The measurements started three hours after ionophore coating of the $\mathrm{ZnO}$ nanowire microelectrode. After this we tested the fabricated microelectrodes inside a $100 \mu \mathrm{l}$ drop of distilled water and did not obtain any signal from it. When the microelectrodes were inside a droplet containing $1 \mathrm{mM} \mathrm{KCl}$ in deionized water a change of the signal was observed within about $30 \mathrm{~s}$. This response behavior indicates that the fabricated sensor is sensitive to a specific metallic ion, i.e. $\mathrm{K}^{+}$. The latency for the detection of $\mathrm{K}^{+}$depends on the number of ionophores located in PVC membrane. With a low density of ionophores it will take a long time to reach equilibrium, while a high density increase the access to the $\mathrm{ZnO}$ nanowires hidden under the PVC cover, thus making the response time faster.

\subsection{Measurements, calibration and specificity of the $\mathbf{K}^{+}$-selective microelectrodes}

After calibration (see Experimental Details), the electrochemical response (EMF) was measured in the $\mathrm{K}^{+}$ solutions for the concentrations ranging from $1 \mu \mathrm{M}$ and $125 \mathrm{mM}$. The tested sensor configuration showed a large dynamic range with an EMF linearly related to the logarithm of $\mathrm{K}^{+}$concentration between $25 \mu \mathrm{M}$ to 125 $\mathrm{mM}$. The slope was $41.5 \mathrm{mV} /$ decade as shown in figure 2. The selectivity is very important parameter which describes the specificity towards the target ion in the presence of other interfering ions. To investigate common interferents normally present inside cells we prepared two types of $\mathrm{K}^{+}$solutions. One solution was prepared with 85 $\mathrm{mM} \mathrm{KCl}$ in deionized water. The other one was prepared with $85 \mathrm{mM} \mathrm{K}^{+}$in PBS in which we have introduced the possible interfering ions such as $235 \mathrm{mM} \mathrm{Na}^{+}, 1 \mu \mathrm{M} \mathrm{Ca}^{2+}$ and $500 \mu \mathrm{M} \mathrm{Mg}^{2+}$. Good selectivity was observed from the output response curves with and without interfering ions. This can be clearly seen in figure 3(a) that shows that the response of the sensor is quite stable for $\mathrm{K}^{+}$in deionized water without interfering ions, while figure 3(b) shows negligible noise in the response due to the mixing of interfering ions in the solutions. The $\mathrm{pH}$ effect on the sensor performance was investigated over the $\mathrm{pH}$ range from 2 to 10 for $1 \mu \mathrm{M}$ to $125 \mathrm{mM}$ of $\mathrm{K}^{+}$. The corresponding potential values obtained were independent of $\mathrm{pH}$ in the range 4 to 8 . Deviations in sensor potential were observed at $\mathrm{pH}$ values above and below this range due to dissolving phenomena of $\mathrm{ZnO}$ nanowires. 


\subsection{Measurements in two different cell types}

To measure the electrochemical potential in human adipocytes, we used micromanipulators to move the two electrodes gently into the cell. When the $\mathrm{K}^{+}$selective and the reference microelectrodes were inside the cell, the electrochemical potential difference could be recorded and analyzed. The intracellular $\mathrm{K}^{+}$concentration in single human adipocyte was $83 \pm 10 \mathrm{mM}(\mathrm{n}=5)$, The only other published data we have found for adipocytes is $177 \mathrm{mM}$ in primary rat adipocytes determined from the steady-state accumulation of ${ }^{86} \mathrm{Rb}^{+}$[43].

In a second set of experiment, we measured the intracellular $\mathrm{K}^{+}$concentration in frog oocytes in a similar way. The intracellular concentration was $110 \pm 20 \mathrm{mM}$ (n $=5$ ), which was close to what has been reported before: 92 (large oocyte), 117 (mature oocyte), 120 (oocyte with the follicle cell layer), and $150 \mathrm{mM}$ (large oocyte) [44]. In order to study the stability and reproducibility of the fabricated sensor, eight sensor electrodes were prepared independently; four electrodes were used to measure the $\mathrm{K}^{+}$concentration in human adipocytes and four other electrodes were used to measure the $\mathrm{K}^{+}$concentration in frog oocytes. Figure 4(a-b) shows the good reproducibility for the measurements.

The insertion of thin $\mathrm{K}^{+}$-selective $\mathrm{ZnO}$ nanowire-based microelectrodes into the cytoplasm of single living cells did not visibly seem to affect cellular viability. However, larger microelectrodes affected the viability of the penetrated cells. Thus, the viability depends strongly on the dimensions of the electrode tip. This study demonstrated that the small size of the sensing microelectrode made it a minimally invasive tool appropriate for monitoring $\mathrm{K}^{+}$inside living cells of the size used in the present investigation. The morphology of the membrane-coated $\mathrm{K}^{+}$-selective microelectrode was checked by scanning electron microscopy directly after measurements. Some debris from the cell and the cell membrane adhere to the electrode tip and possibly this contamination occurs mainly when the electrode tip is pulled out from the cell after the measurements (Fig. 1(d)). In any case the electrochemical response of the electrode does not seem to be affected, which is in line with what could be expected from a potentiometric device as long as the blockage of the active surface is only partial. We have attempted to clean the stuck cell components from the electrode after intracellular measurements but due to the fragile nature of electrode tip, it is often broken down during cleaning process. Hence we recommend this proposed sensor as disposable sensor.

\section{Conclusion}

In conclusion, we have described the construction of a $\mathrm{K}^{+}$-selective microelectrode based on $\mathrm{ZnO}$ nanowires grown on a thin glass tip and coated by a valinomycin-containing $\mathrm{K}^{+}$-selective membrane. This sensor showed a response time of less than $30 \mathrm{~s}$ and a quite wide linear range from $25 \mu \mathrm{M}$ to $125 \mathrm{mM} \mathrm{K}^{+}$with minimum detection level of $1 \mu \mathrm{M}$. The sensor showed a good performance in sensitivity, stability, selectivity, reproducibility and small interference from other ions. Furthermore, the sensor is easy to fabricate and easy to insert in large cells. The measured intracellular $\mathrm{K}^{+}$ concentrations in single human adipocytes and frog oocytes were consistent with values found in the literature. These results pave the way to perform biologically relevant measurements of $\mathrm{K}^{+}$inside living cells. 


\section{References}

[1] J. J. R. Frausto da Silva and R. J. P. Williams, "The biological Chemistry of the Elements", $2^{\text {nd }}$ Ed. Oxford University Press, Oxford, 2001

[2] J. Bernstein, "Untersuchungen zur thermodynamic der bioelektrischen ströme", Pflügers Arch, vol. 92, pp. 521-562, 1902

[3] B. Hille, "Ion Channels of Excitable Membranes", $3^{\text {rd }}$ Ed, Sinauer Associates, Sunderland, MA, 2001

[4] W. Kuschinsky , M. Wahl, O. Bosse and K. Thurau, "Perivascular potassium and $\mathrm{pH}$ as determinants of local pail arterial diameter in cats: A micro application study", Circ Res, vol.31, pp.240-247, 1972

[5] F. J. Gennari, "Disorders of potassium homeostasis. Hypokalemia and hyperkalemia", Crit. Care Clin, vol. 18, pp. 273-288, 2002

[6] A. Rastergar and M. Soleimani, "Hypokalaemia and hyperkalaemia", Postgrad. Med. J., vol. 77, pp. 759-764, 2001

[7] M. H. Hsieh, C.Y Cheng, P. Chan, C.T. Tai and S.A. Chen, "Monophasic action potential-like electrocardiogram simulating acute myocardial infarction", J. Interv. Card. Electr., vol. 8, pp. 41-44, 2003

[8] W. Annan, N. A. Kirwan, W.S. Robertson, P.R. Teasdale and B. P. Ager, "An evaluation of the NOVA 1 ion selective electrode analyzer for sodium and potassium determination", J. Autom. Chem., vol. 2, pp. 212-218, 1980

[9] A. Minta and R.Y. Tsien, "Fluorescent indicators for cytosolic sodium”, J. Biol. Chem., vol. 264, pp. 1944919457, 1989

[10] R. Crossley, Z. Goolamali and P.G. Sammes, "Synthesis and properties of a potential extracellular fluorescent probe for potassium", J. Chem. Soc. Perkin Trans., vol. 2, pp. 1615- 623, 1994

[11] H. Ueyama, M. Takagi and S. Takenaka, “ A novel potassium sensing in aqueous media with a synthetic oligonucleotide derivative. fluorescence resonance energy transfer associated with guanine quartetpotassium ion complex formation", J. Am. Chem. Soc., vol. 124, pp.14286-14287, 2002

[12] F. He, Y. Tang, S. Wang, Y. Li and D. Zhu, “ Fluorescent amplifying recognition for DNA Gquadruplex folding with a cationic conjugated polymer: a platform for homogeneous potassium detection', J. Am. Chem. Soc., vol. 127, pp. 12343-12346, 2005

[13] S.P. Yu, L.M.T. Canzoniero and D.W. Choi, "Ion homeostasis and apoptosis", Curr. Opin. Cell Biol, vol. 13, pp.405-411, 2001

[14] F. Zhang, X. Wang, S. Ai, Z. Sun, Q. Wan, Z Zhu, Y. Xian, L. Jin and K. Yamamoto, " Immobilization of uricase on $\mathrm{ZnO}$ nanorods for a reagentless uric acid biosensor", Anal. Chim. Acta., vol. 519, pp. 155-160, 2004

[15] S. P. Singh, S. K. Arya, P. Pandey, B. D. Malhotra, S. Saha, K. Sreenivas, and V. Gupta, "Cholesterol biosensor based on rf sputtered zinc oxide nanoporous thin film", Appl. Phys. Lett., vol. 91, pp. 063901063903, 2007

[16] P. Hung Yeh, Z. Li and Z. L. Wang, " SchottkyGated Probe-Free ZnO Nanowire Biosensor", $A d v$. Mater., vol. 21, pp. 4975- 4978, 2009

[17] T. Y. Wei, P. H. Yeh, S.Y. Lu and Z. L. Wang, "Gigantic enhancement in sensitivity using schottky contacted nanowire nanosensor", J. Am. Chem. Soc., vol. 131, pp. 17690-17695, 2009

[18] N. Kumar, A. Dorfman and J.I. Hahm, "Ultrasensitive DNA sequence detection using nanoscale ZnO sensor arrays", Nanotechnol., vol.17, pp. 28752881, 2006

[19] Q. Wan, Q. H. Li, Y. J. Chen, T. H. Wang, X. L. He, J. P. Li and C. L. Lin, "Fabrication and ethanol sensing characteristics of $\mathrm{ZnO}$ nanowire gas sensors", Appl. Phys. Lett.., vol. 84, pp. 3654-3656, 2004

[20] E. Topoglidis, E. Palomares, Y. Astuti, A. Green, C. J. Campbell and J. R. Durrant, "Immobilization and electrochemistry of negatively charged proteins on modified nanocrystalline metal oxide electrodes", Electroanal.,, vol. 17, pp.1035-1041 , 2005

[21] S. M. Usman Ali, O. Nur, M. Willander and B. Danielsson, "Glucose detection with a commercial MOSFET using a $\mathrm{ZnO}$ nanowires extended gate", IEEE T. Nanotechnol, vol. 8, pp. 678 - 683, 2009

[22] J. X. Wang, X. W. Sun, A. Wei, Y. Lei, X. P. Cai, C. M. Li and Z. L. Dong, "Zinc oxide nanocomb biosensor for glucose detection", Appl. Phys. Lett, vol. 88, pp. 233106-233109, 2006

[23] T. V. Dinh, P. Kasili and M. Wabuyele, "Nanoprobes and nanobiosensors for monitoring and imaging individual living cells", Nanomedicine, vol. 2, pp. 22-30, 2006. 
[24] N. A. Kouklin, W. E. Kim, A. D. Lazareck and J. M. $\mathrm{Xu}$, "Carbon nanotube probes for single-cell experimentation and assays", Appl. Phys. Lett, vol. 87,pp. 173901-173903, 2005

[25] R. Fasching, E. Tao, S. J. Bai, K. Hammerick, L. Smith, R. Greco and F. Prinz, in " Nanoscale Technology in biology systems", edited by R. Greco, F. Prinz and R. L. Smith (CRC, Boca Raton, FL, 2005), pp. 55-72.

[26] M. Firtela, G. Henderson and I. Sokolov, “ Nanosurgery: observation of peptidoglycan strands in Lactobacillus helveticus cell walls", Ultramicroscopy, vol. 101, pp. 105-109, 2004

[27] M. H. Asif, A. Fulati,O. Nur, M. Willander, C. Brännmark, P. Strålfors, S.I. Börjesson and F. Elinder, "Functionalized zinc oxide nanorod with ionophoremembrane coating as an intracellular $\mathrm{Ca}^{2+}$ selective sensor' , Appl. Phys. Lett, vol. 95, pp. 023703-23705, 2009

[28] M. H. Asif, S. M. Usman Ali, O. Nur, M. Willander, C. Brännmark, P. Strålfors, U. H. Englund, F. Elinder and B. Danielsson, "Functionalized ZnO-nanorod-based selective electrochemical sensor for intracellular glucose", Biosens. Bioelectron. (In press), doi:10.1016/j.bios.2010.02.025, 2010

[29] A. Noy ${ }^{a}$ *, A. B. Artyukhin ${ }^{\mathrm{b}}$ and N. Misra, 'Bionanoelectronics with 1D materials', Materialstoday, vol. 12, pp. 22-31, 2009

[30] U. Yogeswaran and S.M. Chen *, "A review on the electrochemical sensors and biosensors composed of nanowires as sensing material', Sensors, vol. 8, pp. 290-313, 2008

[31] E. Bakker, P. Buhlmann, and E. S. I. Pretsch, "Polymer membrane ion-selective electrodes-what are the limits?', Electroanal., vol. 11, pp. 915-933, 1999

[32] E. Bakker, P. Buhlmann, and E. S. I. Pretsch, 'Carrier-based ion-selective electrodes and bulk optodes. 1. general characteristics", Chem. Rev., vol. 97, pp. 3083-30132, 1997

[33] E. Bakker, P. Buhlmann, and E. S. I. Pretsch, 'Carrier-based ion-selective electrodes and bulk optodes. 2. ionophores for potentiometric and optical sensors", Chem. Rev., vol. 98, pp. 1593-1687, 1998.

[34] K. Neupert-Laves and M. Dobler, "The crystal structure of a K ${ }^{+}$complex of valinomycin', Helv. Chim. Acta., vol. 58, pp. 432-442, 1975
[35] J. H. Morain-Cabral, Y. Zhou and R. MacKinnon, "Energetic optimization of ion conduction rate by the $\mathrm{K}^{+}$ selectivity filter', Nature, vol. 414, pp. 37-42, 2001

[36] K. C Oh ${ }^{\mathrm{a}}$, E. C. Kang ${ }^{\mathrm{a}}$, Y. L. Cho ${ }^{\mathrm{b}}$, K. S. Jeong ${ }^{\mathrm{b}}$, E.

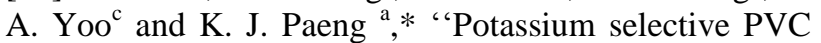
membrane electrode based on newly synthesized cis-and trans- bis (crown ether)s', Ana. Sci., vol.14, pp. 11091012, 1998

[37] L. E. Greene, M. Law, J. Goldberger, F. Kim, J. C. Johnson, Y. Zhang, R. J. Sayekally and P. Yang, "General route to vertical $\mathrm{ZnO}$ nanowire arrays using textured $\mathrm{ZnO}$ seeds', Angew. Chem. Int. Ed., vol.42, pp. 3031-3034, 2003

[38] L. Vayssieres, K. Keis, S. E. Lindquist and A. Hagfeldt, " Purpose-built anisotropic metal oxide material: 3D highly oriented microrod array of $\mathrm{ZnO}$ ', $J$. Phys. Chem., vol.105, pp. 3350-3352, 2001

[39] Q. Li, V. Kumar, Y. Li, H. Zhang, T. J. Marks, R. P. H. Chang, "Fabrication of $\mathrm{ZnO}$ nanorods and nanotubes in aqueous solutions", Chem. Mater, vol. 17, pp.1001-1006, (2005)

[40] P. Strålfors and R. C. Honnor, "Insulin-induced dephosphorylation of hormone-sensitive Lipase correlation with lipolysis and cAMP-dependent protein kinase activity', Eur. J. Biochem., vol. 182 , pp. 379-85, 1989

[41] A. Danielsson, A. Öst, E. Lystedt, P. Kjolhede,J. Gustavsson, F. H. Nyström and, P. Strålfors, "Insulin resistance in human adipocytes occurs downstream of IRS1 after surgical cell isolation but at the level of phosphorylation of IRS 1 in type 2 diabetes", FEBS $J$, vol. 272, pp. 141-151, 2005

[42] S. I. Börjesson, T. Parkkari, S. Hammarström and F. Elinder, "Electrostatic tuning of cellular excitability", Biophys. J., vol. 98, pp. 396-403, 2010

[43] M. D. Resh, R. A. Nemenoff, and G Guidotti, “ Insulin stimulation of $\left(\mathrm{Na}^{+}, \mathrm{K}^{+}\right)$-adenosine triphosphatasedependent ${ }^{86} \mathrm{Rb}^{+}$uptake in rat adipocytes", J. Biol. Chem. vol. 255, pp. 10938-10945, 1980

[44] N. Dascal, "The use of Xenopus oocytes for the study of ion channels', CRC Crit Rev Biochem, vol. 22, pp. 317-387, 1987

* Corresponding author: Syed M. Usman Ali

( E-mail: syeal@itn.liu.se ) 


\section{Figure 1}

\section{Figure 2}
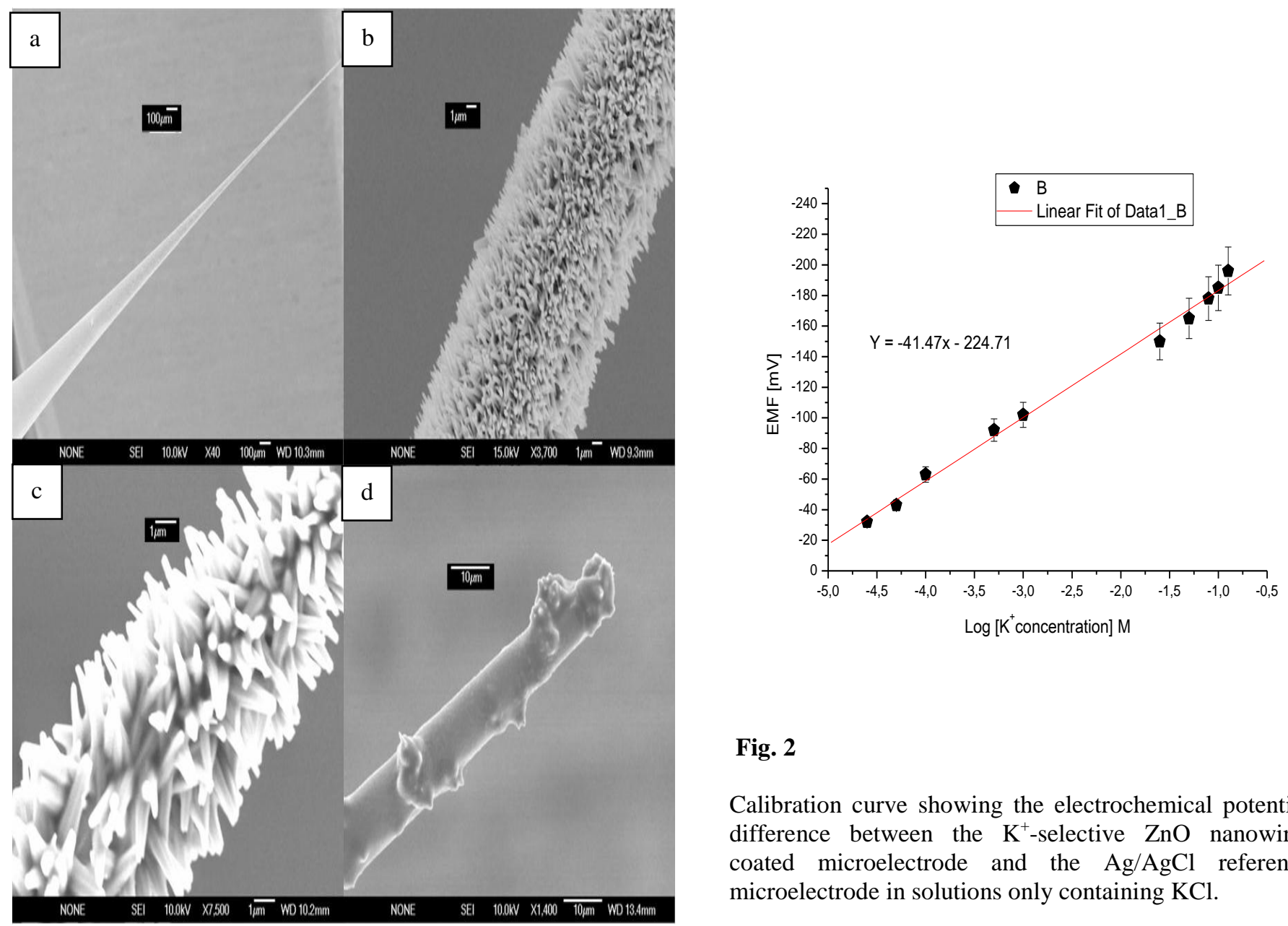

Fig. 2

Calibration curve showing the electrochemical potential difference between the $\mathrm{K}^{+}$-selective $\mathrm{ZnO}$ nanowirecoated microelectrode and the $\mathrm{Ag} / \mathrm{AgCl}$ reference microelectrode in solutions only containing $\mathrm{KCl}$.

Fig.1 (a-b) Scanning electron microscope images at different magnifications of the $\mathrm{ZnO}$ nanowires grown on $\mathrm{Ag}$-coated glass capillary using low temperature growth.

Fig.1 (c) The $\mathrm{ZnO}$ nanowires covered with transparent layer of $\mathrm{K}^{+}$selective membrane.

Fig.1 (d) The $\mathrm{K}^{+}$selective electrode after intracellular Measurements.

Legend: Fig.1 (a-b) the size of the scale bars is $100 \mu \mathrm{m}$ and $1 \mu \mathrm{m}$ respectively where as in parts (c-d) the size of the scale bars are $1 \mu \mathrm{m}$ and $10 \mu \mathrm{m}$ respectively. 


\section{Figure 3}

(a)

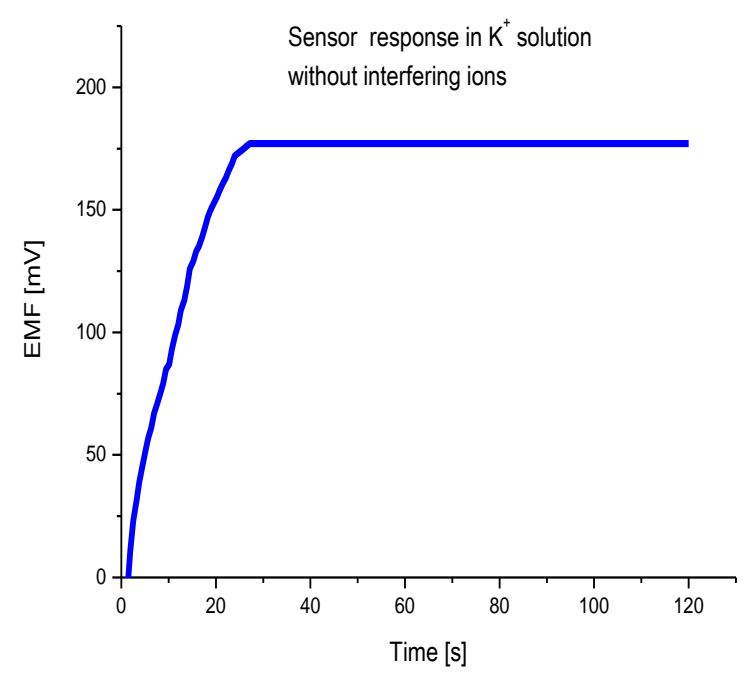

(b)

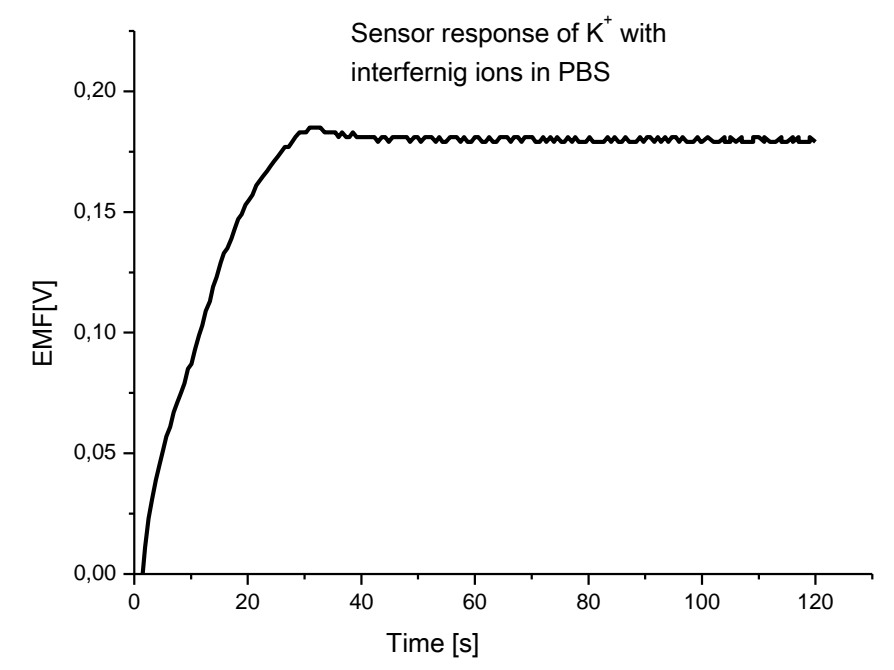

Fig.3 (a-b) The time response of the measurement of the signal in two $\mathrm{K}^{+}$solutions of $85 \mathrm{mM} \mathrm{KCl}$ without and with interfering ions $\left(\mathrm{Na}^{+}, \mathrm{Ca}^{2+}\right.$ and $\left.\mathrm{Mg}^{2+}\right)$

\section{Figure 4}

(a)

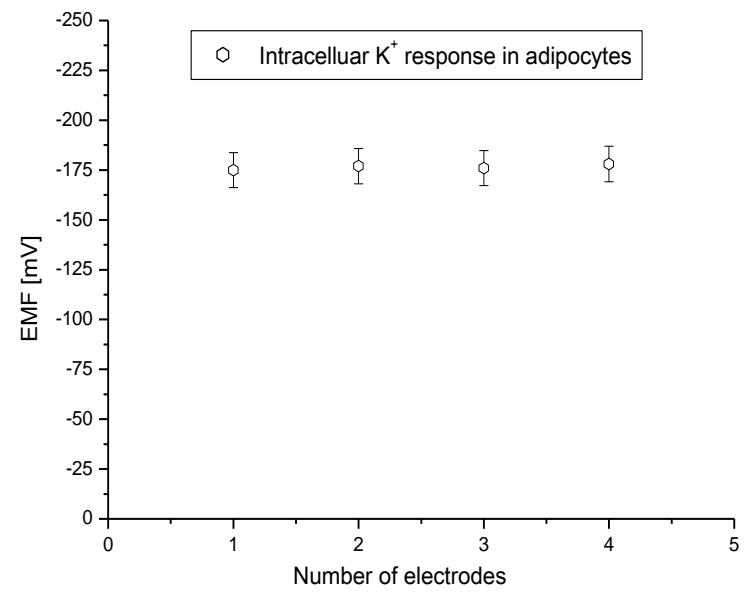

(b)

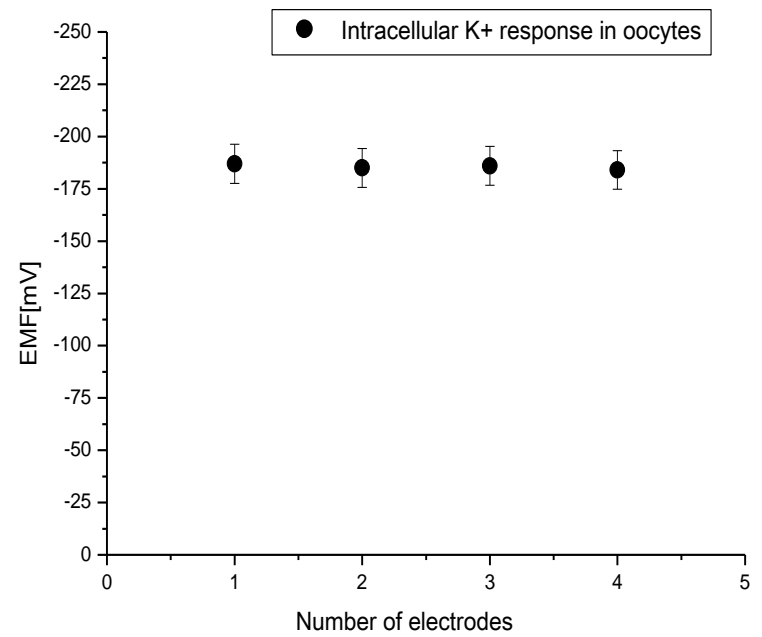

Fig.4 (a-b) The sensor-to-sensor reproducibility of four $\mathrm{K}^{+}$-selective microelectrodes for human adipocytes (a) and frog oocytes(b) 


\section{Corresponding author: Syed M. Usman Ali} (E-mail: syeal@itn.liu.se)

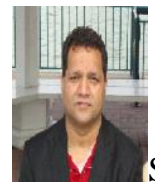

Syed Muhammad Usman Ali received the B.E degree in Electronic Engineering from (DCET) NED University of Engineering \& Technology Karachi, Pakistan in 1993 and the M Sc. (Electrical Engineering) in Power electronics and computer systems in 2000 from NED university of Engineering \& Technology Karachi, Pakistan.

Syed M. Usman Ali is an assistant Professor in Department of Electronic Engineering at NED University of Engineering and Technology Karachi, Pakistan. He is currently a PhD student in the Department of Science and Technology, (Physical Electronics and Nanotechnology Division) Campus Norrköping, Linköping University, SE-601 74 Norrköping, Sweden. His current research interests are based on $\mathrm{ZnO}$ nano-structures characterization and device development for technical and medical applications. $\mathrm{He}$ is also involved in the fabrication and characterization of micro and nano photonics devices (Nanoelectronics).

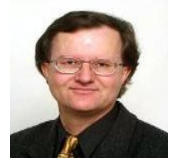

Magnus Willander has M.Sc degrees from Lund University, (physics), Uppsala University (engineering physics) and Stockholm University (economy) and $\mathrm{PhD}$ degree in physics from Royal Institute of Technology in Stockholm. Dr Willander worked five years with electronic design in different industries in the 70s and 80s. In the 80s he did pioneering work on $\mathrm{SiGe}, \mathrm{SiC}$ and polymer transistors as associate professor in Linköping University. In 1995 he was appointed to full professor in nanoscience in Gothenburg University, where he continued to work on more fundamental problems related to tunneling, collective phenomena like BEC, stochastic phenomena etc. In the beginning of 2000 Prof. Willander extended his work to more soft materials and liquids. Around 2002 he started his work on $\mathrm{ZnO}$ nanostructures. In 2005 Willander become professor in Linköping University where he has continued to work on $\mathrm{ZnO}$ nanostructures and its interaction with soft materials etc. During 2006 and 2009 he was also guest professor in Gothenburg University. He has also several times been guest scientist in nanoscience in Tokyo Institute of Technology, Tokyo. In the above mention research areas Prof. Willander has published numerous numbers of experimental and theoretical refereed articles and eight books.

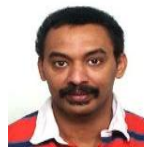

Physics during 1986 from the University of Khartoum,
Sudan and the Ph.D. degree during 1996 in Device Physics from the University of Linköping, Sweden. His research interest is in device physics and technology. At present Dr. Omer Nur is an associate professor and holds a senior lecturer position at the Department of Science and Technology, Campus Norrköping, Linköping University, Sweden. His current research interest is synthesis, characterization and device development based on $\mathrm{ZnO}$ nano-structures for technical and medical applications. He has published over 120 articles in international journal and in reviewed conference proceedings.

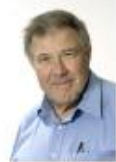

Bengt Danielsson joined Pure and Applied Biochemistry, Lund University 1975 realizing various biosensor developments, such as the 'enzyme thermistor' and "enzyme transistors". He became $\mathrm{PhD}$ in biochemistry 1979 and associate professor (docent) in biochemistry 1982. His current research interests are focused on bioanalysis and biosensor development and practical biomedical and environmental applications including miniaturized sensor-chips for home and in and ex vivo monitoring. Studies on thermometric and optical sensors as well as electrochemical and optothermal techniques has resulted in over 200 publications. Recent work involves nanotechnology (e.g. $\mathrm{ZnO}$ nanowires), bioaffinity arrays and micropattern formation studied by surface plasmon resonance, ellipsometry, scanning probe microscopy and chemiluminescent and fluorescent immuno- and molecular imprinting assays.

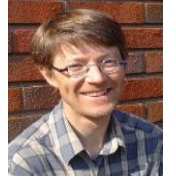

Fredrik Elinder studies voltage-gated ion channels with a focus on the molecular mechanism of voltage sensitivity. He received his $\mathrm{PhD}$ at Karolinska Institutet, Stockholm, Sweden, and is now professor of Molecular Neurobiology at Linköping University.

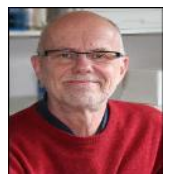

Peter Strålfors investigates the cell and molecular biology of adipocytes, with a special focus on insulin signaling and type 2 diabetes. Strålfors is a full professor in medical cell biology at Linköping University.

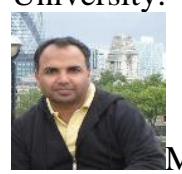

Phil in Physics from University of Punjab Lahore, Pakistan in 2002 and 2005. He is currently a PhD student in Linkoping University, Department of Science and Technology (ITN), Physical Electronics and Nanotechnology group, Norrkoping Campus, Sweden. 
He has defended his Licentiate degree in August 2009. His research interest is the potential application of $\mathrm{ZnO}$ nanorods as Photodynamic therapy and electrochemical biosensors for extra/intracellular environment.

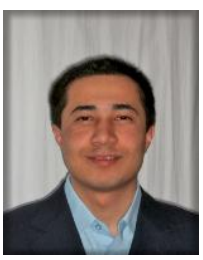

Alimujiang Fulati received his B.S. in Electronic Science and Technology from Fudan University, Shanghai, China in 2005 and M.S. in Nanoscale Science and Technology, Chalmers University of Technology, Göteborg, Sweden in 2007. He completed his Ph.D. in Physical Electronics at Linköping University, Sweden in 2010. His research interest includes fabrication of advanced nanomaterials, their mechanical characterization, and electrochemical and biosensor application of nanomaterials.

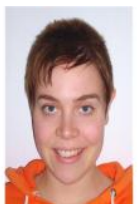

Cecilia Brännmark is currently a $\mathrm{PhD}$ student in Linkoping University, department of Clinical and Experimental Medicine. She investigates human adipocytes with special interest in insulin signaling and type 2 diabetes.

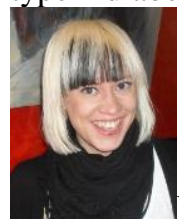
department of Clinical and Experimental Medicine at Linköping University. Her main research focus is on the role of plasma membrane ion channels in apoptosis. 